\title{
The effect of a Janda-based stretching program range of motion, muscular strength, and pain in middle-aged women with self-reported muscular skeletal symptoms
}

\author{
Ji-Eun Kim, Tae-Beom Seo, Young-Pyo Kim* \\ Department of Kinesiology, College of Natural Science, Jeju National University, Jeju, Korea
}

The purpose of this study was to investigate the effect of a stretching program, based on the Janda approach and compared with a static stretching program, on range of motion (ROM), muscle strength and pain. Subjects for this study were 11 middle-aged women with self-reported muscular skeletal symptoms. The subjects were randomly divided into six women as an experimental group (stretching based on Janda approach group, SJAG) and five women as the comparison group (traditional static stretching group, TSSG). Static stretching program in both groups consisted of 14 types of exercise and strength program in SJAG was comprised of five isometric contractions. The stretching program was performed 3 times per week for 6 weeks. The ROM and muscle strength of the neck and shoulder region were measured and a nu- merical rating scale was used for measuring pain. Significant differences between groups were determined with two-way repeated analysis of variance and paired $t$-test. As a result of this study, the ROM did not show generally significant changes but was affirmatively improved in both groups. SJAG showed significant improvement in muscle strength and pain reduction compared to the TSSG. Consequently, a stretching program based on the Janda approach would be more effective on self-reported muscular skeletal symptoms caused by posture misalignment than a static stretching program.

Keywords: Janda program, Range of motion, Muscular strength, Pain

\section{INTRODUCTION}

Natural spine alignment is one of the important factors for a healthy life because it decreases the load on the body joints and prevents deformation of one's posture. A modified spinal alignment leads to abnormal morphological changes in the musculoskeletal system induced by the range of motion (ROM) reduction and muscle imbalance, which causes functional restriction of physical activity with pain (Nussbaumer et al., 2010).

ROM is influenced by muscle tightness resulting from an increase in active tension. It has been well known that limitations of ROM in human joints for an extended period may induce a variety of physical problems including illness, injury, poor posture, and muscle imbalances. In the field of sports medicine, many researchers have recommended and emphasized the importance of flexibility and muscle strength to treat a body imbalance (Rubini et al., 2007). In particular, Gleim and McHugh (1997) suggested that flexibility might be a mediator to prevent limitation of ROM in target joints through increase of muscle elasticity as well as Paolucci et al. (2018) and Berglund et al. (2018) reported that increase in muscle strength could maintain the body's alignment by preventing mechanical deformation of the spine. With these results mentioned by previous studies, an active stretching program with flexibility and muscle strength may improve the quality of life for patients suffering from pain induced by ROM restriction.

Based on these theories, Janda $(1983,1986)$ developed a stretching and strength exercise program for musculoskeletal pain relief such as protecting the pained tissues and recovering proper body alignment, which named Janda approach. And then Page (2012), a disciple of Janda, redefined the concrete exercise method and the

\footnotetext{
${ }^{*}$ Corresponding author: Young-Pyo Kim (D) https://orcid.org/0000-0001-6662-1393 Department of Kinesiology, College of Natural Science, Jeju National University, 102 Jejudaehak-ro, Jeju 63243, Korea

E-mail: kimyp@jejunu.ac.kr

Received: December 7, 2018 / Accepted: January 11, 2019
}

This is an Open Access article distributed under the terms of the Creative Commons Attribution Non-Commercial License (http://creativecommons.org/licenses/by-nc/4.0/) which permits unrestricted non-commercial use, distribution, and reproduction in any medium, provided the original work is properly cited. 
effectiveness of the Janda approach. After re-establishment, Yuktasir and Kaya (2009) reported that isometric exercise with static stretching for 6 weeks further improved ROM of patients with functional limitation of joints compared to those in static stretching group. Also Page (2011) confirmed that a stretching program based on the Janda approach decreased the pain caused by subacromial impingement of athletes who were involved in overhead sports such as baseball and swimming.

However, previous studies focused on pain relief in young patients and athletes with medical diagnosis. There are few studies on the effect of the Janda approach when applied to middle-aged women with self-report muscular skeletal symptoms. Therefore, the purpose of this study was to investigate the effect of a stretching program based on the Janda approach in regards to the ROM, muscular strength and pain in middle-aged women with self-report muscular skeletal symptoms.

\section{MATERIALS AND METHODS}

\section{Participants}

The participants in this study were 16 middle-aged women with self-reported muscular skeletal symptoms, whose limitations of ROM and moderate pain in the neck and shoulder were indicated.
Specifically, all participants were classified between grade 3 and grade 1 in the evaluation criteria of the manual muscle test reported by Kelly et al. (1996). But five of the participants were excluded by revealing their intention to give up during the experiment. As shown in Table 1, all participants were randomly allocated to the traditional static stretching group (TSSG, $n=5$ ) and the Janda approach stretching group (SJAG, $n=6$ ). Before beginning the study, all participants had a detailed explanation of this study and submitted their written informed consent to researchers. This research was conducted ethically according to international guidelines.

\section{Therapeutic stretching program}

Janda's approach is one of the therapeutic strategies that have

Table 1. The characteristics of the subjects

\begin{tabular}{lrc}
\hline Variable & TSSG $(\mathrm{n}=5)$ & SJAG $(\mathrm{n}=6)$ \\
\hline Age $(\mathrm{yr})$ & $34.20 \pm 1.79$ & $36.67 \pm 8.48$ \\
Height $(\mathrm{cm})$ & $162.58 \pm 4.15$ & $163.63 \pm 6.03$ \\
Weight $(\mathrm{kg})$ & $65.72 \pm 7.31$ & $64.87 \pm 10.00$ \\
\hline
\end{tabular}

Values are presented as mean \pm standard deviation.

TSSG, traditional static stretching group; SJAG, stretching based on Janda approach group.

Table 2. Stretching program

\begin{tabular}{|c|c|c|c|c|}
\hline Group & Application & No. of items & Event & Time \\
\hline TSSG & Static stretching & 14 & $\begin{array}{l}\text { Neck flexor stretch } \\
\text { Neck extensor stretch } \\
\text { Neck rotator stretching } \\
\text { Shoulder extensor, adductor, retractor stretch } \\
\text { Shoulder adductor, elevator, protractor stretch } \\
\text { Elbow extensor stretch } \\
\text { Back extensor \& hip external rotator stretch } \\
\text { Hip adductor \& knee flexor stretch } \\
\text { Lower trunk lateral flexor \& knee extensor stretch } \\
\text { Hip \& back extensor stretch } \\
\text { Knee flexor stretch } \\
\text { Hip external rotator \& extensor stretch } \\
\text { Lower trunk flexor stretch } \\
\text { Hip flexor, knee extensor, shoulder protractor stretch }\end{array}$ & $15 \mathrm{sec}$ for each \\
\hline SJAG & $\begin{array}{l}\text { Static stretching } \\
\text { Isometric contraction }\end{array}$ & $\begin{array}{r}14 \\
5\end{array}$ & $\begin{array}{l}\text { As above } \\
\text { Abdominal isometric contraction with lower trunk flexor stretch } \\
\text { Cervical extensor isometric contraction in vertebra upright position } \\
\text { Lumbar extensor isometric contraction in vertebra upright position } \\
\text { Shoulder internal rotator Isometric contraction } \\
\text { Shoulder flexor \& retractor isometric contraction }\end{array}$ & $\begin{array}{l}15 \mathrm{sec} \text { for each } \\
3 \mathrm{sec}, 3 \text { times for each }\end{array}$ \\
\hline
\end{tabular}

TSSG, traditional static stretching group; SJAG, stretching based on Janda approach group. 
received attention in the field of chronic pain management. We performed a modified stretching program, according to a previously described method (Mine et al., 2017). As shown in Table 2, the static stretching program in both TSSG and SJAG consisted of 14 types of exercise and strength program in SJAG was comprised of 5 isometric contractions. All programs were done 3 times per week for 6 weeks. Static stretching in two groups was performed holding the stretch for at least $15 \mathrm{sec}$ (Page, 2012) and isometric exercise was conducted three times in a maximum contraction mode for $3 \mathrm{sec}$ under the supervision of a certified expert.

\section{ROM assessment}

ROM was measured by goniometer (Orthopedic Equipment Co., Bourbon, IN, USA) that is reliable and extensively used in the field of anthropometry. All examiners were experienced professionals with a rehabilitation therapist license. Passive neck extension, rotation and lateral bending were analyzed with standard goniometry in sitting position (Nussbaumer et al., 2010).

\section{Manual muscle test}

Manual muscle test is a popular test method that has high validity and reliability to confirm muscle strength in patients with musculoskeletal problems (Cuthbert and Goodheart, 2007). ROM and functional problems of each joint of the participants with pain were confirmed and all assessments are based on the evaluation criteria of the manual muscle test suggested by Gleim and McHugh (1997).

\section{Numeric rating scale}

In the clinical setting, numeric rating scale (NRS) is an evaluation tool for patients with pain in the musculoskeletal system, which is simple and easy to apply (Krebs et al., 2007; Mannion et al., 2007). Examiner measures the pain level through the subject's interview and the pain range is a 0 to 10 scores. A score of ' 0 ' indicates no pain and '10' means severe pain (Hawker et al., 2011).

\section{Statistical analysis}

PASW Statistics ver. 18.0 (SPSS Inc., Chicago, IL, USA) was used to determine the effect of a stretching program based on the Janda approach. To confirm the main effect, we used a two-way repeated analysis of variance. If there was a significant interaction effect, an independent $t$-test between groups or a paired $t$-test between times was applied. All values are expressed as mean \pm standard deviation. $P<0.05$ was considered significant.
Table 3. The result for range of motion of each joint with pain (measurement: ${ }^{\circ}$ )

\begin{tabular}{|c|c|c|c|c|}
\hline Variable & Group & Pre & Post & F-value \\
\hline \multirow[t]{2}{*}{ Neck extension ROM } & SSG & $28.00 \pm 2.74$ & $29.00 \pm 2.24$ & G×P: 0.872 \\
\hline & $A G$ & $67 \pm 5.16$ & $30.00 \pm 0.001$ & \\
\hline \multirow[t]{2}{*}{ Left neck rotation ROM } & TSSG & $46.00 \pm 2.24$ & $49.00 \pm 4.18$ & $G \times P:$ \\
\hline & SJAG & $40.83 \pm 6.65$ & $48.33 \pm$ & \\
\hline \multirow[t]{2}{*}{ Right neck rotation ROM } & TSSG & 44.0 & $44.00 \pm 2.23$ & .0 .001 \\
\hline & SJAG & $48.33 \pm 4.08$ & $48,33 \pm$ & \\
\hline \multirow{2}{*}{$\begin{array}{l}\text { Left neck lateral bending } \\
\text { ROM }\end{array}$} & $S G$ & 0 & 45.00 & G×P: 0.905 \\
\hline & $A G$ & 7 & 45.0 & \\
\hline \multirow{2}{*}{$\begin{array}{l}\text { Right neck lateral } \\
\text { bending ROM }\end{array}$} & $G$ & 2 & 4 & 0.700 \\
\hline & SJAG & $40.83 \pm 6.65$ & $45.00 \pm$ & \\
\hline \multirow{2}{*}{$\begin{array}{l}\text { Left shoulder internal } \\
\text { rotation ROM }\end{array}$} & SSG & $73.20 \pm 8.84$ & 76.00 & G×P: 0.120 \\
\hline & SJAG & $73.67 \pm 7.66$ & 79.17 & \\
\hline \multirow{2}{*}{$\begin{array}{l}\text { Right shoulder internal } \\
\text { rotation ROM }\end{array}$} & SSG & $76.00 \pm 4.18$ & 76.00 & $G \times P: 1.488$ \\
\hline & SJAG & $76.67 \pm 6.06$ & $80.00=$ & \\
\hline \multirow{2}{*}{$\begin{array}{l}\text { Left shoulder external } \\
\text { rotation ROM }\end{array}$} & TSSG & $59.00 \pm 2.24$ & $60.00 \pm 0.001$ & G×P: 0.722 \\
\hline & SJAG & $55.83 \pm 8.01$ & $60.00 \pm 0.001$ & \\
\hline \multirow{2}{*}{$\begin{array}{l}\text { Right shoulder external } \\
\text { rotation ROM }\end{array}$} & TSSG & $52.60 \pm 4.88$ & $56.20 \pm 2.77^{*}$ & D: 0.010 \\
\hline & SJAG & $56.17 \pm 4.49$ & $60.00 \pm 0.001$ & \\
\hline
\end{tabular}

Values are presented as mean \pm standard deviation.

TSSG, traditional static stretching group; SJAG, stretching based on Janda approach group; $\mathrm{ROM}$, range of motion; $\mathrm{G} \times \mathrm{P}$, group $\times$ period.

${ }^{*} P<0.05$, significantly different from pretest. ${ }^{\dagger} P<0.05$, significantly interaction among group and period.

\section{RESULTS}

\section{Change in ROM of each joint with pain}

Changes of ROM of each joint with pain before and after a stretching program based on the Janda approach are shown in Table 3. ROM of the left neck rotation and right neck rotation in SJAG were significantly increased over time compared to TSSG, and ROM of right shoulder external rotation showed significant difference only in TSSG. Although ROM of left neck rotation ( $F=$ $1.858, P=0.045)$ showed interaction between two groups, ROM of neck extension $(F=0.872, P=0.375)$, the right neck rotation $(F=0.001, P=1.000)$, the left neck lateral bending $(F=0.905$, $P=0.366)$, the right neck lateral bending $(F=0.459, P=0.515)$, the left shoulder internal rotation $(F=0.120, P=0.737)$, the right shoulder internal rotation $(F=1.488, P=0.254)$, the left shoulder external rotation $(F=0.722, P=0.417)$, and the right shoulder external rotation $(F=0.010, P=0.921)$ showed no relative effects between groups or over time.

\section{Change in muscle strength}

Changes in muscle strength before and after a stretching program based on the Janda approach are shown in Table 4. Strength 
Table 4. The result for muscle strength

\begin{tabular}{|c|c|c|c|c|}
\hline Variable & Group & Pre & Post & F-value \\
\hline \multirow[t]{2}{*}{ Neck extensor strength } & TSSG & $4.00 \pm 1.37$ & $4.20 \pm 1.15$ & $G \times P: 3.593$ \\
\hline & SJAG & $4.17 \pm 1.29$ & $4.67 \pm 0.52$ & \\
\hline \multirow[t]{2}{*}{ Left neck rotator strength } & TSSG & $4.80 \pm 0.45$ & $4.80 \pm 0.45$ & $G \times P: 6.8$ \\
\hline & SJAG & $3.33 \pm 1.29$ & $4.67 \pm 0.52^{*}$ & \\
\hline \multirow[t]{2}{*}{ Right neck rotator strength } & TSSG & $3.60 \pm 1.08$ & $44.00 \pm 2.23$ & $G \times P: 2.267$ \\
\hline & SJAG & 4.00 & $41^{*}$ & \\
\hline \multirow{2}{*}{$\begin{array}{l}\text { Left neck lateral bending } \\
\text { muscle strength }\end{array}$} & TSSG & 3.20 & $.84^{*}$ & $G \times P: 4.909$ \\
\hline & & & & \\
\hline \multirow{2}{*}{$\begin{array}{l}\text { Right neck lateral bending } \\
\text { muscle strength }\end{array}$} & & & & $G \times P: 0.211$ \\
\hline & SJA & $4.00 \pm 1.22$ & $4.58 \pm 0.66$ & \\
\hline \multirow{2}{*}{$\begin{array}{l}\text { Left shoulder internal } \\
\text { rotator strength }\end{array}$} & TSSG & $3.80 \pm 1.25$ & $4.20 \pm 0.76$ & $G \times P: 0.495$ \\
\hline & SJAG & $4.25 \pm 0.99$ & $5.00 \pm 0.00$ & \\
\hline \multirow{2}{*}{$\begin{array}{l}\text { Right shoulder internal } \\
\text { rotator strength }\end{array}$} & TCSR & $3.30 \pm 1.15$ & $3.70 \pm 0.91$ & $G \times P: 0.628$ \\
\hline & SJAG & $4.17 \pm 1.29$ & $4.67 \pm 0.52$ & \\
\hline \multirow{2}{*}{$\begin{array}{l}\text { Left shoulder external } \\
\text { rotation ROM }\end{array}$} & TSSG & $3.60 \pm 0.65$ & $4.00 \pm 1.06$ & $G \times P: 3.273$ \\
\hline & SJAG & $3.67 \pm 0.98$ & $4.67 \pm 0.52$ & \\
\hline \multirow{2}{*}{$\begin{array}{l}\text { Right shoulder external } \\
\text { rotator strength }\end{array}$} & TSSG & $3.40 \pm 1.08$ & $3.80 \pm 1.15$ & GxP: 0.144 \\
\hline & SJAG & $4.17 \pm 0.68$ & $4.67 \pm 0.52^{*}$ & \\
\hline
\end{tabular}

Values are presented as mean \pm standard deviation.

TSSG, traditional static stretching group; SJAG, stretching based on Janda approach group; $\mathrm{ROM}$, range of motion; $\mathrm{G} \times \mathrm{P}$, group $\times$ period.

${ }^{*} P<0.05$, significantly different from pretest. ${ }^{\dagger} P<0.05$, significantly interaction among group and period.

of the left neck rotator, right neck rotator and right shoulder external rotator were significantly increased over time compared to TSSG, and the left neck lateral bending muscle strength showed significant difference in both SJAG and TSSG. Although strength of the left neck rotator $(F=6.890, P=0.028)$ showed interaction between two groups, strength of the neck extensor $(F=3.593$, $P=0.091)$, the right neck rotator $(F=2.267 P=0.166)$, the left neck lateral bending muscle $(F=4.909, P=0.054)$, the right neck lateral bending muscle $(F=0.211, P=0.657)$, the left shoulder internal rotator $(F=0.495, P=0.500)$, the right shoulder internal rotator $(F=0.628, P=0.449)$, the left shoulder external rotator $(F=3.273, P=0.104)$, and the right shoulder external rotator $(F=$ $0.144, P=0.713$ ) showed no relative effects between groups or over time.

\section{Change in the pain NRS}

To examine the pain NRS, we performed the interview before and after stretching program based on Janda approach. As shown in Table 5, NRS score $(F=20.928, P=0.001)$ showed interaction between two groups and SJAG had a significant decrease over time compared to those in TSSG.
Table 5. The result for the numeric rating scale (NRS)

\begin{tabular}{lcccc}
\hline Variable & Group & Pre & Post & F-value \\
\hline NRS & TSSG & $5.60 \pm 1.34$ & $4.20 \pm 0.45$ & G $\times$ P: $20.928^{\dagger}$ \\
& SJAG & $6.83 \pm 1.17$ & $1.83 \pm 0.75^{*}$ & \\
\hline
\end{tabular}

Values are presented as mean \pm standard deviation.

TSSG, traditional static stretching group; SJAG, stretching based on Janda approach group; $\mathrm{G} \times \mathrm{P}$, group $\times$ period.

${ }^{*} P<0.05$, significantly different from pretest. ${ }^{\dagger} P<0.05$, significantly interaction among group and period.

\section{DISCUSSION}

The Janda approach to stretching exercise is one of the therapeutic tools for improvement of musculoskeletal dysfunction, consisting of static stretching and isometric contraction exercises. To performing Janda approach stretching exercises, flexibility and muscle strength are very important factors.

Most previous studies suggested that muscle stretching and strengthening exercises such as pilates provided benefits in improvement of ROM in the joints and muscle strength (Aladro-Gonzalvo et al., 2012; Curnow et al., 2009). Not only Ahearn et al. (2018) identified that flexibility exercise increased muscle strength and body alignment in gymnasts but also Watson et al. (2017) reported the effect of regular stretching and strength exercises on improvement of ROM, pelvic-lumbar stability, and muscle functions in normal adults.

Muscular strength exercise is a critical regulator that improves shortening the muscle-tendon length and stabilizes the posture alignment of the human body. And stretching exercise increases flexibility with improving ROM of each joint. Yuktasir and Kaya (2009) reported that static stretching exercise with isometric exercise 4 times a week for 6 weeks significantly increased ROM of the joint compared to only static stretching exercise. Also a previous study on effectiveness of stretching and strengthening exercise emphasized that these types of stretching exercises are beneficial in increasing strength of abdominals and gluteals, and enhancing flexibility of rectus femoris, iliopsoas and erector spinae (Hrysomallis and Goodman, 2001). A present study confirmed similar results that Janda-approach stretching exercise further improved ROM of the left neck rotation and right neck rotation in SJAG over time, and ROM of left neck rotation showed interaction between two groups rather than those in TSSG. We think that these positive alterations of stretching and strength exercise are due to the contraction of the antagonistic muscle leading to isometric contraction of the agonistic muscle.

Pain is a common cause of ROM limitation and decreased mus- 
cle contraction, which leads to muscle weakness. Graven-Nielsen et al. (2002) reported a close relationship between ROM and muscle strength in patients with chronic pain. This study examined whether pain was significantly different between the treatment period and the group, and there were also interactions with the group and the treatment period. In previous studies, sensorimotor training similar to Janda approach stretching exercises has been proven to improve proprioceptive sensory function, muscular strength, and skeletal alignment in ankle instability (Freeman et al., 1965), knee instability (Ihara and Nakayama, 1986), and after anterior cruciate ligament surgery (Nyland et al., 2017). It is thus considered a relevant therapeutic method to decrease pain and increase muscle strength for patients with self-report muscular skeletal symptoms.

Taken together, self-reported muscular skeletal symptoms are a medical condition that adversely affects daily life and lowers the quality of life. And Janda approach stretching exercises, consisting of stretching and isometric exercise, for 6 weeks increased ROM of the joint and muscular strength as well as decreased pain. Therefore our findings provide important evidence that Janda approach stretching exercise may be effective tools to improve body composition, the ROM, muscular strength and pain in middle-aged women with self-report musculoskeletal symptoms.

\section{CONFLICT OF INTEREST}

No potential conflict of interest relevant to this article was reported.

\section{ACKNOWLEDGMENTS}

This research was supported by the 2018 scientific promotion program funded by Jeju National University.

\section{REFERENCES}

Ahearn EL, Greene A, Lasner A. Some effects of supplemental Pilates training on the posture, strength, and flexibility of dancers 17 to 22 years of age. J Dance Med Sci 2018;22:192-202.

Aladro-Gonzalvo AR, Machado-Díaz M, Moncada-Jiménez J, HernándezElizondo J, Araya-Vargas G. The effect of Pilates exercises on body composition: a systematic review. J Bodyw Mov Ther 2012;16:109-114.

Berglund L, Aasa B, Michaelson P, Aasa U. Sagittal lumbopelvic alignment in patients with low back pain and the effects of a high-load lifting exercise and individualized low-load motor control exercises-a random- ized controlled trial. Spine J 2018;18:399-406.

Curnow D, Cobbin D, Wyndham J, Boris Choy ST. Altered motor control, posture and the Pilates method of exercise prescription. J Bodyw Mov Ther 2009;13:104-111.

Cuthbert SC, Goodheart GJ Jr. On the reliability and validity of manual muscle testing: a literature review. Chiropr Osteopat 2007;15:4.

Freeman MA, Dean MR, Hanham IW. The etiology and prevention of functional instability of the foot. J Bone Joint Surg Br 1965;47:678-685.

Gleim GW, McHugh MP. Flexibility and its effects on sports injury and performance. Sports Med 1997;24:289-299.

Graven-Nielsen T, Lund H, Arendt-Nielsen L, Danneskiold-Samsøe B, Bliddal $\mathrm{H}$. Inhibition of maximal voluntary contraction force by experimental muscle pain: a centrally mediated mechanism. Muscle Nerve 2002;26:708-712.

Hawker GA, Mian S, Kendzerska T, French M. Measures of adult pain: Visual Analog Scale for Pain (VAS Pain), Numeric Rating Scale for Pain (NRS Pain), McGill Pain Questionnaire (MPQ), Short-Form McGill Pain Questionnaire (SF-MPQ), Chronic Pain Grade Scale (CPGS), Short Form-36 Bodily Pain Scale (SF-36 BPS), and Measure of Intermittent and Constant Osteoarthritis Pain (ICOAP). Arthritis Care Res (Hoboken) 2011;63 Suppl 11:S240-252.

Hrysomallis C, Goodman C. A review of resistance exercise and posture realignment. J Strength Cond Res 2001;15:385-390.

Thara $\mathrm{H}$, Nakayama A. Dynamic joint control training for knee ligament injuries. Am J Sports Med 1986;14:309-315.

Janda V. On the concept of postural muscles and posture in man. Aust J Physiother 1983;29:83-84.

Janda V. Some aspects of extracranial causes of facial pain. J Prosthet Dent 1986;56:484-487.

Kelly BT, Kadrmas WR, Speer KP. The manual muscle examination for rotator cuff strength. An electromyographic investigation. Am J Sports Med 1996;24:581-588.

Krebs EE, Carey TS, Weinberger M. Accuracy of the pain numeric rating scale as a screening test in primary care. J Gen Intern Med 2007;22: 1453-1458.

Mannion AF, Balagué F, Pellisé F, Cedraschi C. Pain measurement in patients with low back pain. Nat Clin Pract Rheumatol 2007;3:610-618.

Mine K, Nakayama T, Milanese S, Grimmer K. Effectiveness of stretching on posterior shoulder tightness and glenohumeral internal-rotation deficit: a systematic review of randomized controlled trials. J Sport Rehabil 2017;26:294-305.

Nussbaumer S, Leunig M, Glatthorn JF, Stauffacher S, Gerber H, Maffiuletti NA. Validity and test-retest reliability of manual goniometers for measuring passive hip range of motion in femoroacetabular impingement patients. BMC Musculoskelet Disord 2010;11:194. 
Nyland J, Gamble C, Franklin T, Caborn DNM. Permanent knee sensorimotor system changes following ACL injury and surgery. Knee Surg Sports Traumatol Arthrosc 2017;25:1461-1474.

Page P. Current concepts in muscle stretching for exercise and rehabilitation. Int J Sports Phys Ther 2012;7:109-119.

Page P. Shoulder muscle imbalance and subacromial impingement syndrome in overhead athletes. Int J Sports Phys Ther 2011;6:51-58.

Paolucci T, Zangrando F, Palladino D, Monaco A, Cordiani B, Mannocci A, Saraceni VM, Villani C. The sagittal spinal alignment in young swimmers and glide performance: the importance of lumbar lordosis.
J Sports Med Phys Fitness 2018;58:1555-1557.

Rubini EC, Costa AL, Gomes PS. The effects of stretching on strength performance. Sports Med 2007;37:213-224.

Watson T, Graning J, McPherson S, Carter E, Edwards J, Melcher I, Burgess T. Dance, balance and core muscle performance measures are improved following a 9-week core stabilization training program among competitive collegiate dancers. Int J Sports Phys Ther 2017;12:25-41.

Yuktasir B, Kaya F. Investigation into the long-term effects of static and PNF stretching exercises on range of motion and jump performance. J Bodyw Mov Ther 2009;13:11-21. 